Article

\title{
Functional Role of Aspergillus carbonarius AcOTAbZIP Gene, a bZIP Transcription Factor within the OTA Gene Cluster
}

\author{
Donato Gerin ${ }^{1}{ }^{(\mathbb{C}}$, Federica Garrapa ${ }^{1}$, Ana-Rosa Ballester ${ }^{2}{ }^{(D)}$, Luis González-Candelas ${ }^{2}{ }^{(D)}$, \\ Rita Milvia De Miccolis Angelini ${ }^{1,3, *}$, Francesco Faretra ${ }^{1,3}$ and Stefania Pollastro ${ }^{1,3}$ (B) \\ 1 Department of Soil, Plant and Food Sciences, University of Bari Aldo Moro, Via Giovanni Amendola, 165/A, \\ 70126 Bari, Italy; donato.gerin@uniba.it (D.G.); f.garrapa1@studenti.uniba.it (F.G.); \\ francesco.faretra@uniba.it (F.F.); stefania.pollastro@uniba.it (S.P.) \\ 2 Food Biotechnology Department, Instituto de Agroquímica y Tecnología de Alimentos (IATA-CSIC), \\ Calle Catedrático Agustín Escardino 7, 46980 Paterna, Valencia, Spain; ballesterar@iata.csic.es (A.-R.B.); \\ lgonzalez@iata.csic.es (L.G.-C.) \\ 3 SELGE Network of Public Research Laboratories, Via Amendola, 165/A, 70126 Bari, Italy \\ * Correspondence: ritamilvia.demiccolisangelini@uniba.it
}

Citation: Gerin, D.; Garrapa, F.; Ballester, A.-R.; González-Candelas, L.; De Miccolis Angelini, R.M.; Faretra, F.; Pollastro, S. Functional Role of Aspergillus carbonarius AcOTAbZIP Gene, a bZIP Transcription Factor within the OTA Gene Cluster. Toxins 2021, 13, 111. https://doi.org/10.3390/ toxins13020111

Received: 31 December 2020

Accepted: 27 January 2021

Published: 2 February 2021

Publisher's Note: MDPI stays neutral with regard to jurisdictional claims in published maps and institutional affiliations.

Copyright: (c) 2021 by the authors. Licensee MDPI, Basel, Switzerland. This article is an open access article distributed under the terms and conditions of the Creative Commons Attribution (CC BY) license (https:// creativecommons.org/licenses/by/ $4.0 /)$.

\begin{abstract}
Aspergillus carbonarius is the principal fungal species responsible for ochratoxin A (OTA) contamination of grapes and derived products in the main viticultural regions worldwide. In recent years, co-expressed genes representing a putative-OTA gene cluster were identified, and the deletion of a few of them allowed the partial elucidation of the biosynthetic pathway in the fungus. In the putative OTA-gene cluster is additionally present a bZIP transcription factor (AcOTAbZIP), and with this work, A. carbonarius $\triangle A c O T A b Z I P$ strains were generated to study its functional role. According to phylogenetic analysis, the gene is conserved in the OTA-producing fungi. A Saccharomyces cerevisiae transcription factor binding motif (TFBM) homolog, associated with bZIP transcription factors was present in the A. carbonarius OTA-gene cluster no-coding regions. AcOTAbZIP deletion results in the loss of OTA and the intermediates OTB and OT $\beta$. Additionally, in $\triangle A c O T A b Z I P$ strains, a downregulation of AcOTApks, AcOTAnrps, AcOTAp450, and AcOTAhal genes was observed compared to wild type (WT). These results provide evidence of the direct involvement of the AcOTAbZIP gene in the OTA biosynthetic pathway by regulating the involved genes. The loss of OTA biosynthesis ability does not affect fungal development as demonstrated by the comparison of $\triangle A c O T A b Z I P$ strains and WT strains in terms of vegetative growth and asexual sporulation on three different media. Finally, no statistically significant differences in virulence were observed among $\triangle A c O T A b Z I P$ strains and WT strains on artificially inoculated grape berries, demonstrating that OTA is not required by A. carbonarius for the pathogenicity process.
\end{abstract}

Keywords: Aspergillus carbonarius; OTA biosynthesis; bZIP transcription factor; gene deletion; gene expression; pathogenicity; secondary metabolism

Key Contribution: OTA and its intermediates were not detected in $\triangle A c O T A b Z I P$ strains. The deletion of AcOTAbZIP led to a down-regulation of the putative-OTA gene cluster. $\triangle A c O T A b Z I P$ strains showed no differences compared to WT in terms of vegetative growth, asexual sporulation, and pathogenicity on grape berries.

\section{Introduction}

Ochratoxin A (OTA) is a mycotoxin with nephrotoxic, carcinogenic, hepatotoxic, neurotoxic, immunosuppressive, and teratogenic effects, classified as a possible carcinogen in humans (group 2B) by the International Agency for Research in Cancer [1].

The fungi responsible for OTA contamination in agricultural products belong mainly to the genus Aspergillus, sections Nigri (e.g., Aspergillus carbonarius and Aspergillus niger), Circumdati (e.g., Aspergillus steynii, Aspergillus westerdijkiae), and Flavi (A. albertensis and 
A. alliaceus), and the genus Penicillium (e.g., Penicillium nordicum and Penicillium verrucosum) [2-7]. In the grapevine cultivated countries of the Mediterranean basin, Aspergillus species of the section Nigri occur more frequently and A. carbonarius is the largest producer of OTA in grape and grape-derived products [8,9].

Co-expressed genes, representing a putative-OTA gene cluster in A. carbonarius were identified by comparing the transcriptome of four OTA-producing strains grown under OTA-inducing and OTA-non inducing conditions. The cluster included a polyketide synthase (AcOTApks), a nonribosomal peptide synthase (AcOTAnrps), and halogenase (AcOTAhal) genes, proved to be directly involved in OTA biosynthesis [10-12], and additionally, a hypothetical protein recently annotated as cyclase [13], a cytochrome P450 monooxygenase (AcOTAp450) and a bZIP transcription factor (AcOTAbZIP) [14]. Recently, the same genes were identified by genomic diversity and RNA-Seq studies comparing A. carbonarius OTA producing and non-producing strains $[15,16]$. In addition, a consensus OTA biosynthetic pathway was identified in A. ochraceus fc-1 (recently re-classified as A. westerdijkiae [17]) by gene deletion approach demonstrating that the AcOTApks, AcOTAnrps, AcOTAP450, AcOTAbZIP, and AcOTAhal orthologue genes of A. carbonarius were directly involved in OTA biosynthesis [18].

Several transcription factors were found to regulate genes involved in the secondary metabolite biosynthesis. These include global transcriptional regulators as AreA (nitrogen regulation; [19,20]); $\mathrm{PaCC}$ ( $\mathrm{pH}$ regulation; [21]); CreA (carbon catabolite repressor; [22,23]); LaeA and VeA (light; [24]); metabolite-specific transcription factors such as AflR a Zn(II)2Cys6, regulating aflatoxins and sterigmatocistin biosynthetic genes [25]; Tri6 and Tri10 (both regulating the expression of trichotecene biosynthetic genes; [26]); and OTAR1 (a bZIP transcription factor involved in OTA biosynthesis in A. westerdijkiae fc-1 [18]).

bZIPs transcription factors are unique to eukaryotes and they are generally identified based on their bZIP domain, which includes a basic region (BR) and a leucine zipper (LZ). The BR is highly conserved, and it is characterized by an invariant $\mathrm{N}-\mathrm{x} 7-\mathrm{R} / \mathrm{K}$ region, while the LZ is composed of several repeats of leucine or other bulky hydrophobic amino acids (Ile, Val, Phe, or Met), and it is arranged exactly nine amino acid residues toward the C-terminus of the BR [27]. bZIP monomers are long $\alpha$-helices that bind specific DNA sequences through the BR and interact through the LZ that mediates the dimerization to form a superimposed coiled-coil structure [28]. This structure, therefore, affects binding characteristics, expression diversity, and gene regulation of the target genes $[27,28]$.

In this study, we deleted the A. carbonarius AcOTAbZIP gene, a bZIP transcription factor included in the putative OTA gene cluster and conserved in OTA-producing fungi. Three deletion mutants were selected and compared with the wild type (WT) for OTA production, vegetative growth, asexual sporulation, and colonization of grape berries by artificial inoculation. Chemical analyses of the OTA-intermediates and gene expression studies were also performed to assess the AcOTAbZIP role in the A. carbonarius OTA-biosynthetic pathway.

\section{Results}

\subsection{Characterization of AcOTAbZIP Gene}

The A. carbonarius AcOTAbZIP gene is located in the scaffold 12 of $A$. carbonarius genome; it is $800 \mathrm{bp}$ in length and encodes a protein of 247 aa (Figure 1a,b). Its orthologues were found in 20 Aspergillus and Penicillium species, and they were located in a putative OTA-biosynthetic gene cluster (Table S1).

Based on the fungal BRLZ domain alignment and the motif prediction of BRLZ domains, it was possible to identify the invariant N-X7-R region typical of the BR domain, the $\mathrm{R}-\mathrm{X} 9-\mathrm{L}$ region that allows distinguishing the BR domain and LZ domain and, at least, four leucine residues in the LZ domain common to all examined fungal species. Additionally, the BRLZ domain of $A$. carbonarius showed four unique amino acid substitutions in the positions $12(\mathrm{~V} / \mathrm{L}), 44(\mathrm{R} / \mathrm{E}, \mathrm{D}, \mathrm{H}, \mathrm{G}, \mathrm{K}, \mathrm{Q}, \mathrm{L}), 46(\mathrm{~L} / \mathrm{I})$, and 47 (S/Q,R,A), respectively in the motif 1 identified by MEME analysis (Figure 1c). 
a
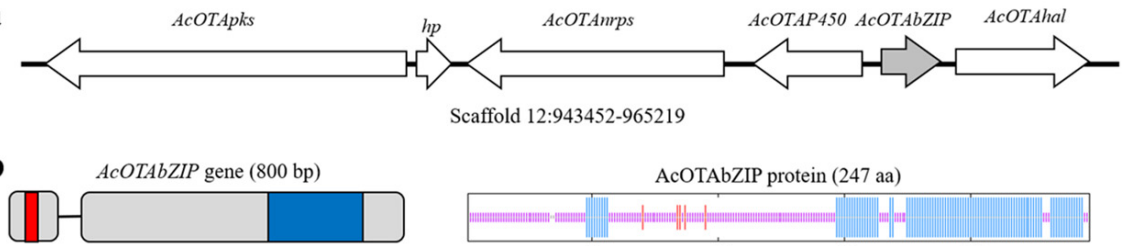

$\square$ exon - intron $\square$ BRLZ $\square$ Low complexity

c

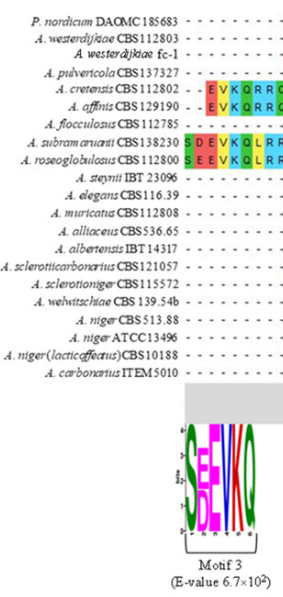

AcOTAbZIP protein (247 aa)
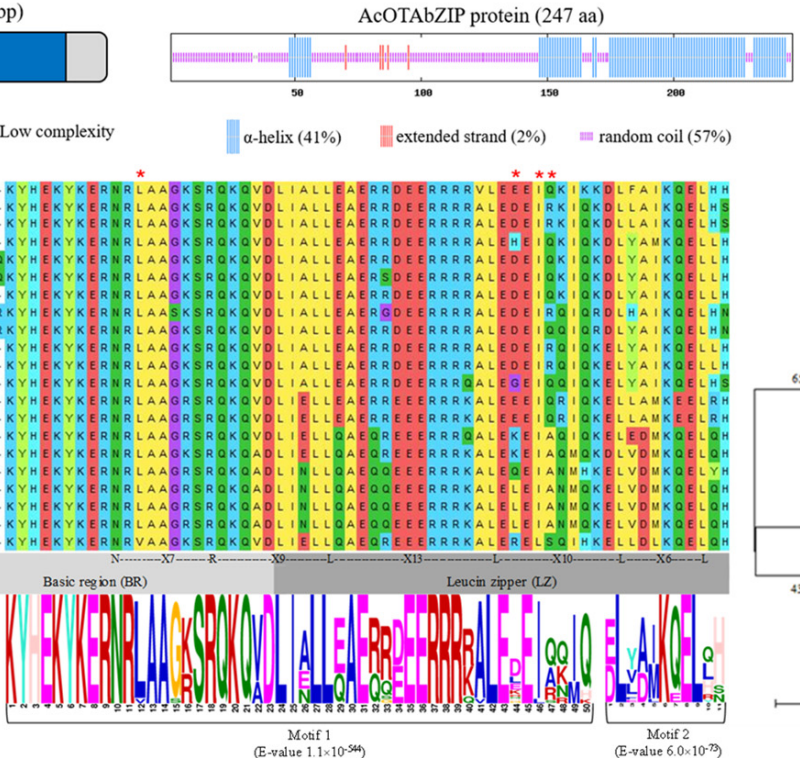

d

19. P. nordicton (DAOMC 185683)

19 P. nordicton (DAOMC $^{\text {A. westijkiae }(f \mathrm{c}-1)}$

24. A. westerdifkiae (CBS 112803)

A. affinis (CBS 129190)

A. cretensis (CBS 112802) A. pulvericola (CBS 137327) A. subramantanti (CBS 138230) A. roseoglobulosus (CBS11280 A. elegans (CBS 11639 ) 40 A. stegnit (IBT 23096) 90 A. Stegnat (ibT 23096) A. albertensis (IBT 1431 ) A. alliacens (CBS 536.65) A. carbonartus (ITEM 5010) 4. A. scierotilicarbonarius (CBS 121057) 69. A. sclerotioniger (CBS115572) 69 A. wehwitschtae (CBS 139.546) 69 A. nitger (lacticoffeatus) (CBS 101883) 91. niger CBS $513.88(167295)$ A6. niger (ATCC 13496)

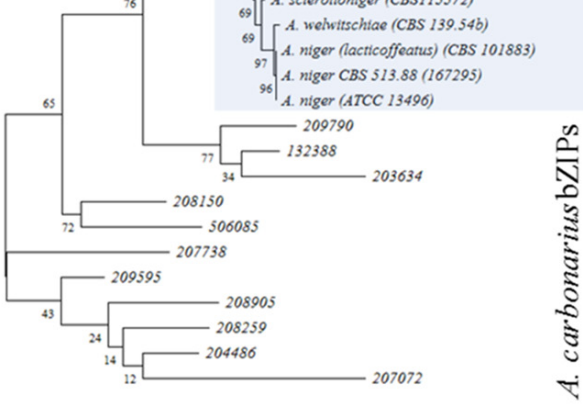

Figure 1. Characterization of AcOTAbZIP gene. (a) location of AcOTAbZIP within the A. carbonarius-OTA gene cluster containing also the AcOTApks, a hypothetical protein ( $h p$, recently annotated as cyclase [13]) coding gene, the AcOTAnrps, the AcOTAP450, and the AcOTAhal genes; (b) in silico analysis of AcOTAbZIP gene and related proteins; (c) alignment of the BR-LZ domain predicted by SMART into each OTAbZIP protein and relative motifs predicted by MEME; (d) phylogenetic analysis by using Maximum Likelihood (ML) method and JTT matrix-based model. In c, red asterisks indicate the amino acids unique to Aspergillus carbonarius. In d, the percentage of trees in which the associated taxa clustered together is shown next to the branches; the tree is drawn to scale, with branch lengths measured in the number of substitutions per site.

According to the BRLZ-phylogenetic analysis, the tree with the highest log likelihood $(-2212.83)$ is shown in Figure 1d. ML analysis showed that the other 11 A. carbonarius bZIP transcription factors annotated in the genome and carrying the BRLZ domain were clustered separately to the OTAbZIP transcription factors of Aspergillus spp. and Penicillium nordicum. According to the ML tree, the subsequent OTAbZIPs were grouped in: (i) A. carbonarius ITEM 5010, (ii) A. niger strains CBS 101883, ATCC 13496 and CBS 513.88, A. sclerotiicarbonarius CBS 121057, A. sclerotioniger CBS 115572 and A. welwitschiae CBS 13954b (section Nigri), (iii) A. albertensis IBT 14317 and A. alliaceus CBS 536.65 (section Flavi), and (iv) A. affinis CBS 129190, A. cretensis CBS 112802, A. elegans CBS 116.39, A. flocculosus CBS 112785, A. muricatus CBS 112808, A. pulvericola CBS 137327, A. roseoglobulosus CBS 112800, A. steynii IBT 23096, A. subramanianii CBS 138230, A. ochraceus fc-1 and A. westerdijkiae CBS 112803 (section Circumdati), and P. nordicum DAOMC 185683 (Figure 1d, Table S2).

The most representative TFBM found by MEME in all fungal species was 15 bases in length (RATGACGTGTARANV) and it occurred in 129 sites into the provided sequences $\left(\right.$ e-value $\left.=3.1 \times 10^{-160}\right)($ Table S3). Additionally, according to TOMTOM analysis, the predicted TFBM showed homology ( $p$-value $\leq 0.01$ ) with TFBM of Saccharomyces cerevisae related to bZIP transcription factors and other classes, such as tryptophan cluster factors, basic helix-loop-helix factors (bHLH), TALE-type homeodomain factors, and APSES-type DNA-binding domain (Table S4).

\subsection{Generation of A. carbonarius Deletion Mutants}

To investigate the role of AcOTAbZIP in OTA biosynthesis, the gene was deleted in the A. carbonarius AC49 strain by replacement with the hygromycin resistance cassette (Figure 2a). 
After co-cultivation of $A$. carbonarius $\left(1.5 \times 10^{4}\right.$ conidia plate $\left.^{-1}\right)$ with $A$. tumefaciens AGL-1 carrying the pRFHU2-AcOTAbZIP plasmid an average of 17 A. carbonarius HygB-resistant colonies per plate were obtained (efficiency: $0.11 \%$ ). Monosporic isolates were obtained after three subcultures on PDA containing $100 \mu \mathrm{g} \mathrm{mL}^{-1}$ hygromycin B (InvivoGen, San Diego, CA, USA), and the PCR pattern corresponding to homologous integration of T-DNA in the target site was assessed (Figure $2 b$ ).

a

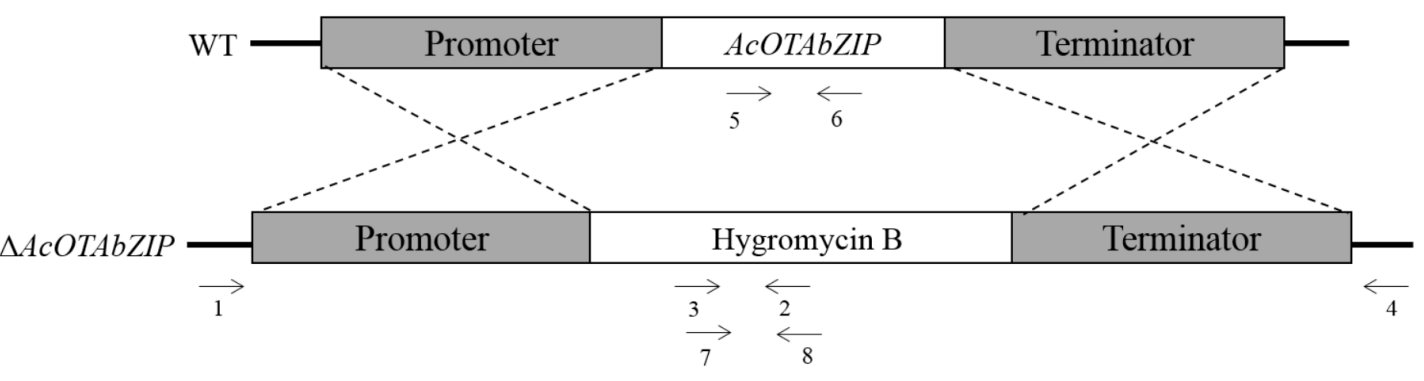

b
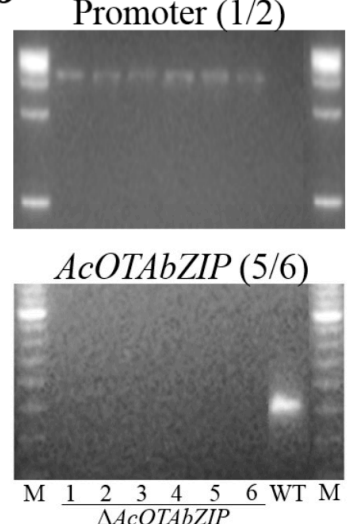

Terminator (3/4)

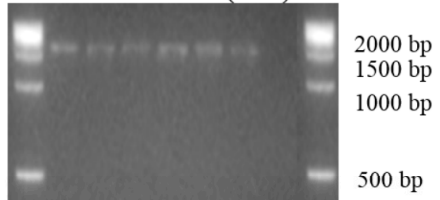

Hygromicin B (7/8)

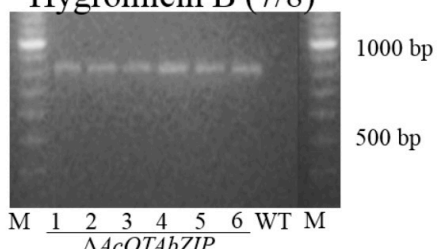

c

\begin{tabular}{cccc}
\hline Strain & Cq (GOI) & Cq (Ref) & CN \\
\hline AC49 & $21.50 \pm 0.07$ & $21.31 \pm 0.13$ & - \\
$\triangle A c O T A b Z I P-1$ & $22.53 \pm 0.22$ & $22.50 \pm 0.01$ & 1.13 \\
$\triangle A c O T A b Z I P-2$ & $22.26 \pm 0.00$ & $22.41 \pm 0.04$ & 1.28 \\
$\triangle 4 c O T A b Z I P-3$ & $22.19 \pm 0.00$ & $22.32 \pm 0.00$ & 1.27 \\
\hline
\end{tabular}

d

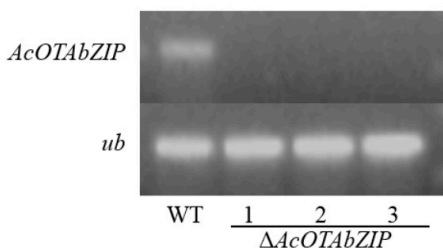

Figure 2. Generation of $\triangle A c O T A b Z I P$ strains. (a) Strategy of gene replacement; primer pairs AcOTAbZIP_1F (1)/HPH1F (2), HPHPRO4 (3)/AcOTAbZIP_2R (4), AcOTAbZIP_3F (5)/AcOTAbZIP_4R (6) and HMBR1 (7)/HMBF1 (8) were used for the amplification of promoter, terminator, AcOTAbZIP and Hygromycin B in the AcOTAbZIP locus, respectively. (b) PCR pattern including the promoter, terminator, AcOTAbZIP, and Hygromycin B amplification products; (c) copy number analysis by qPCR; GOI is AcOTAbZip, Ref is calmodulin and CN indicates copy number. (d) RT-PCR analysis of the AcOTAbZIP gene and the reference gene ubiquitin $(u b)$.

Three selected $\triangle A C O T A b Z I P$ mutants were also assayed for evaluating the number of T-DNA copies integrated into the genome by qPCR using the WT parental strain as control (Figure 2c). The three deletants contained one single event of integration. Finally, the three $\triangle A c O T A b Z I P$ mutants were subjected to RT-qPCR analysis to demonstrate that the AcOTAbZIP gene was not functionally present in the genome of the mutants (Figure $2 \mathrm{~d}$ ). The three $\triangle A c O T A b Z I P$ mutants were then used for the subsequent analyses.

\subsection{Phenotypic Characterization}

No statistical differences regarding in vitro fungal growth and sporulation, and virulence on artificially inoculated grape berries were observed for the three $\triangle A c O T A b Z I P$ mutants compared to the WT strain (Table 1, Figure 3). Under in vitro conditions, 7 DAI at $25^{\circ} \mathrm{C}$, the daily growth rate was $4.2-4.3 \mathrm{~mm} \mathrm{day}^{-1}$ on MM, 7.5-7.6 $\mathrm{mm}^{\text {day }}{ }^{-1}$ on PDA, and $6.4 \mathrm{~mm} \mathrm{day}^{-1}$ on MEA for $\triangle A c O T A b Z I P$ mutants and the WT strain. Seven DAI at $25^{\circ} \mathrm{C}$ all strains produced up to $10.6 \times 10^{4}$ conidia $/ \mathrm{mm}^{2}$ on $\mathrm{MM}, 0.4 \times 10^{4}$ conidia $/ \mathrm{mm}^{2}$ on PDA and $0.5 \times 10^{4}$ conidia $/ \mathrm{mm}^{2}$ on MEA. Daily growth rate of the rotted area on grape berries was $2.9-3.0 \mathrm{~mm} \mathrm{day}^{-1}$ on cv Italia and $2.2-2.3 \mathrm{~mm} \mathrm{day}^{-1}$ on the cv Red Globe (Table 1). 
Table 1. Phenotypic characterization of $\triangle A c O T A b Z I P$ compared to WT.

\begin{tabular}{|c|c|c|c|c|c|c|c|c|}
\hline \multirow{3}{*}{ Strain } & \multicolumn{6}{|c|}{ In Vitro Assay } & \multirow{2}{*}{\multicolumn{2}{|c|}{$\begin{array}{l}\text { Assay on Grape Berries } \\
\text { Growth Rate (mm/day) }\end{array}$}} \\
\hline & \multicolumn{3}{|c|}{ Growth Rate (mm day $\left.{ }^{-1}\right)$} & \multicolumn{3}{|c|}{ Conidia $\left[\left(\right.\right.$ No. $\left.\left.\times 10^{4}\right) / \mathrm{mm}^{2}\right]$} & & \\
\hline & $\mathbf{M M}$ & PDA & MEA & MM & PDA & MEA & Italia & Red Globe \\
\hline WT & $4.2 \pm 0.3 \mathrm{a}$ & $7.6 \pm 0.7 \mathrm{a}$ & $6.4 \pm 0.3 \mathrm{a}$ & $8.2 \pm 0.2 \mathrm{a}$ & $0.4 \pm 0.4 \mathrm{a}$ & $0.5 \pm 0.1 \mathrm{a}$ & $3.0 \pm 0.1 \mathrm{a}$ & $2.3 \pm 0.1 \mathrm{a}$ \\
\hline$\triangle A c O T A b Z I P-1$ & $4.3 \pm 0.3 \mathrm{a}$ & $7.5 \pm 0.7 \mathrm{a}$ & $6.4 \pm 0.3 \mathrm{a}$ & $10.6 \pm 1.0 \mathrm{a}$ & $0.4 \pm 0.3 \mathrm{a}$ & $0.5 \pm 0.1 \mathrm{a}$ & $2.9 \pm 0.1 \mathrm{a}$ & $2.2 \pm 0.1 \mathrm{a}$ \\
\hline$\triangle A c O T A b Z I P-2$ & $4.3 \pm 0.3 \mathrm{a}$ & $7.5 \pm 0.7 \mathrm{a}$ & $6.4 \pm 0.4 \mathrm{a}$ & $7.5 \pm 1.1 \mathrm{a}$ & $0.4 \pm 0.1 \mathrm{a}$ & $0.5 \pm 0.2 \mathrm{a}$ & $3.0 \pm 0.1 \mathrm{a}$ & $2.3 \pm 0.1 \mathrm{a}$ \\
\hline$\triangle A c O T A b Z I P-3$ & $4.3 \pm 0.3 \mathrm{a}$ & $7.5 \pm 0.7 \mathrm{a}$ & $6.4 \pm 0.4 \mathrm{a}$ & $7.5 \pm 1.1 \mathrm{a}$ & $0.4 \pm 0.2 \mathrm{a}$ & $0.5 \pm 0.1 \mathrm{a}$ & $3.0 \pm 0.2 \mathrm{a}$ & $2.2 \pm 0.1 \mathrm{a}$ \\
\hline
\end{tabular}

Data represent mean values \pm standard error. The growth rate $\left(\mathrm{mm} \mathrm{day}^{-1}\right)$ was obtained from the mean values of the ratios between the growth $(\mathrm{mm})$ and the number of days $(2,5$, and 7 days for in vitro assay and 7 and 10 days for in vivo assay, respectively). For each column, values followed by the same letter means did not differ statistically at $p \leq 0.05$ according to Tukey's test. MM, PDA, and MEA: minimal medium, potato dextrose agar, and malt extract agar media, respectively.

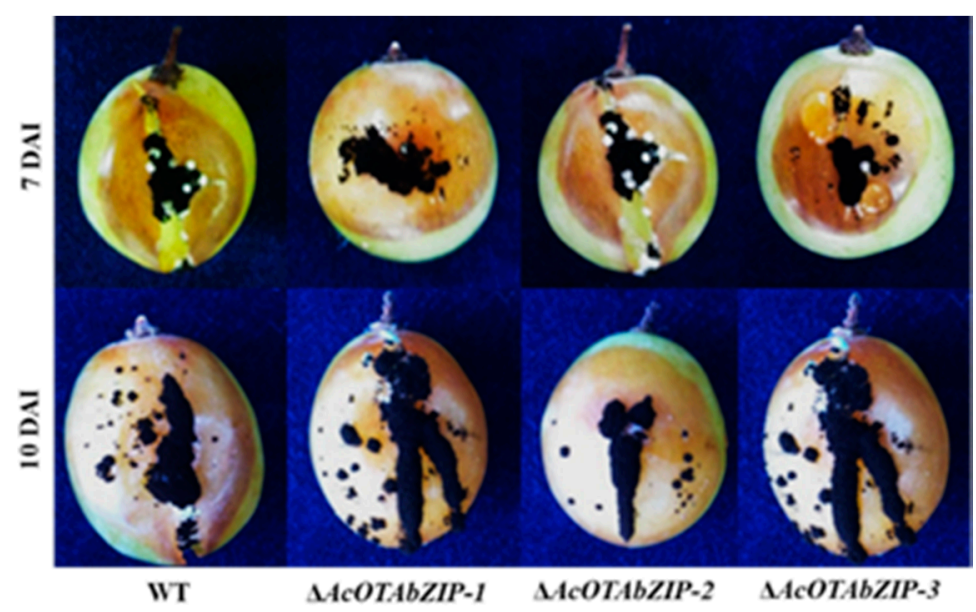

Figure 3. Colonization of wilt type (WT) e deletant $(\triangle A c O T A b Z I P)$ A. carbonarius strains of grape berries of cultivar Italia.

\subsection{Chemical Analysis of OTA and Its Intermediates and Gene Expression Studies}

After 7 days of growth on PDA, the $\triangle A c O T A b Z I P$ strains did not produce OTA compared to WT, which produced $28.8 \pm 3.3 \mathrm{ng} \mu \mathrm{L}^{-1}$ (Figure 4a).

Methanol extracts of PDA-plugs collected from WT and $\triangle A c O T A b Z I P$ cultures were also analyzed for the presence of Phe, 7-MM, OT $\beta$, OTB, and OTA by HPLC-HRMS (Figure $4 \mathrm{~b}$ ). The Phe level was similar in the WT and $\triangle A c O T A b Z I P$ strains in PDA plugs (peak area: 854 and 797, respectively); however, the amount of Phe detected on cultural filtrates was about 2-fold higher in the WT compared to $\triangle A c O T A b Z I P$ strains. Low levels of 7-MM were only detected in the PDA-plugs of the WT strain (peak area: 81), and 7-MM was not detected in those of the $\triangle A c O T A b Z I P$ strain. In the culture filtrates, $7-\mathrm{MM}$ was detected in both WT and $\triangle A c O T A b Z I P$ strains. Levels of this compound were higher for the WT compared to the deletant strain (peak area: 713 and 527, respectively). No OT $\beta$ was detected in either PDA-plugs or culture filtrates of WT and $\triangle A c O T A b Z I P$ strains. Finally, levels of OTB and OTA were only detected in both PDA-plugs and culture filtrates of the WT, with a peak area of OTB in PDA-plugs and culture filtrate of 599.7 and 6934 respectively, and OTA of 6897.7 and 65,359 (Figure $4 \mathrm{~b}$ ).

To verify the role of AcOTAbZIP as the regulator of expression of the OTA biosynthetic genes, a gene expression study was carried out by RT-qPCR. The results showed that after 4 days of growth under OTA inducing conditions, the expression of the OTA biosynthetic genes (AcOTApks, AcOTAnrps, AcOTAP450, and AcOTAhal) was significantly down-regulated in the $\triangle A c O T A b Z I P$ strains $(p \leq 0.05)$ compared to WT (Figure $4 c)$. 
a

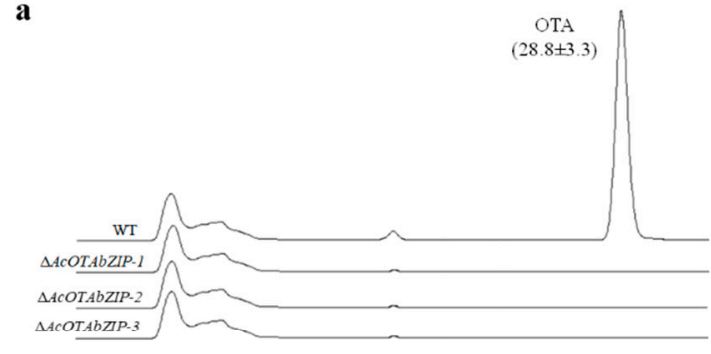

c

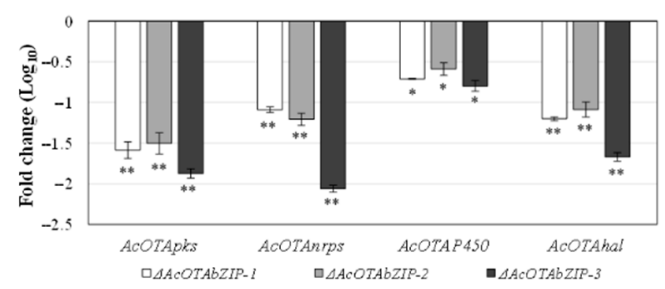

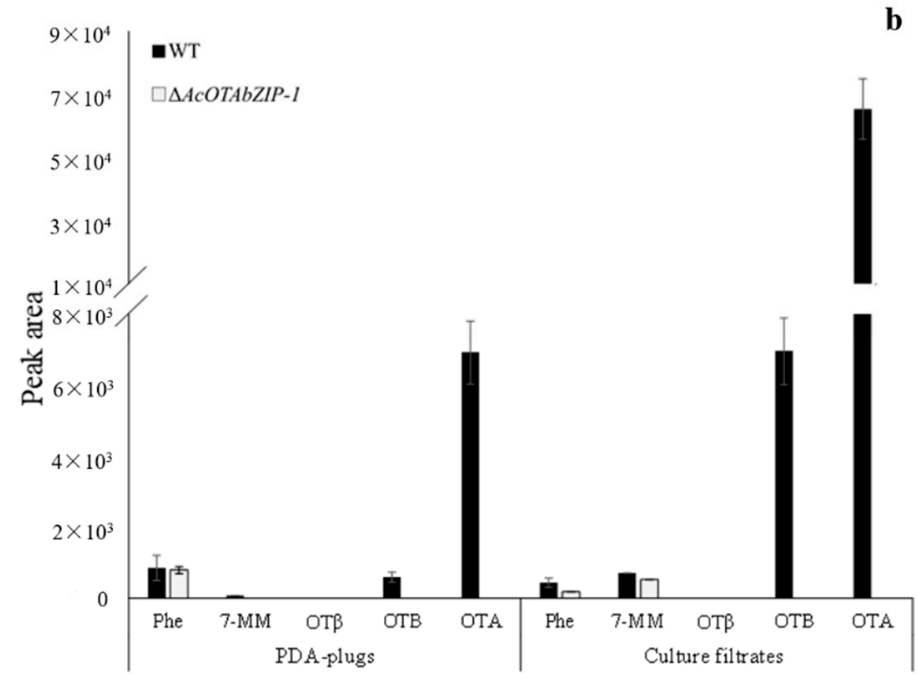

b

Figure 4. Chemical analysis of OTA and its related compounds and gene expression study in WT and $\triangle A c O T A b Z I P$ strains. (a) Preliminary HPLC analysis of OTA and its intermediates [phenyalanine (Phe), 7-methylmellein (7-MM), ochratoxin $\beta$ (OT $\beta$ ), ochratoxin B (OTB)]; (b) HPLC-HRMS analysis of OTA and its intermediate metabolites. Data are the average value \pm standard error; (c) Gene expression analysis. The relative expression value of the three $\triangle A c O T A b Z I P$ strains was compared with that of the WT (fold change). Data are the average value \pm standard error. Significant differences in the relative expression of biosynthetic genes between $\triangle$ AcOTAbZIP strains and WT were assessed at $p \leq 0.05\left(^{*}\right)$ and $p \leq 0.01$ (**) by using Tukey's test.

\section{Discussion}

According to the current knowledge, the A. carbonarius-putative OTA gene cluster includes five biosynthetic genes: (i) the AcOTApks gene encoding the polyketide synthase (PKS) involved in the synthesis of the dihydrocoumarin moiety [11]; (ii) a hypothetical protein, recently annotated as cyclase putatively involved in the polyketide cyclization during the initial step; [13] (iii) the AcOTAP450 gene coding for the cytochrome P450 monooxygenase putatively involved in the dihydrocoumarin C7-oxidation; (iv) the AcOTAnrps gene encoding the non-ribosomal peptide synthase (NRPS) responsible of the peptide bond between dihydrocoumarin with the L-phenylalanine, originating OTB [10]; and (v) the AcOTAhal gene coding for the halogenase (chloroperoxidase) that provides the addition of a chlorine atom to obtain OTA [12]. A fifth highly conserved gene, a basic leucine zipper transcription factor AcOTAbZIP, has also been described to be part of the biosynthetic gene cluster; however, the role of this transcription factor in the OTA biosynthesis of A. carbonarius is still unclear. The present study aimed to functionally characterize this transcription factor by using the ATMT based gene deletion approach and to determine the involvement of this transcription factor in the OTA biosynthesis in A. carbonarius.

The recent availability of fungal genomes allowed the identification of AcOTAbZIPorthologue genes being part of putative gene clusters in other 20 OTA-producing strains. Recently, the putative OTA gene cluster was identified in $A$. westerdijkiae $\mathrm{fc}-1$ and the deletion of the AcOTAbZIP-orthologue gene (OtaR1) blocked the OTA biosynthesis [18]. These authors also proposed that OtaR1 is probably a pathway-specific regulator that controls OTA production by regulating the biosynthetic genes in A. westerdijkiae fc- 1 .

In our study, the BR-LZ domain of OTAbZIP proteins of Aspergillus spp. and P. nordicum clustered together, and they were separated from the BR-LZ domains of other A. carbonariusbZIP transcription factors, indicating their conserved specialization in the OTA biosynthesis. The prediction of TFBMs in the upstream, downstream, and intergenic regions of the Aspergillus spp. and P. nordicum putative OTA gene cluster allowed the identification of a TFBM of 15 bp including a conserved "TGACGTGTA" sequence. This result is in agreement with previous work that showed the identification of this conserved feature in the OTA 
gene cluster of five OTA-producing species (A. carbonarius, A. niger, Aspergillus steynii, and Aspergillus westerdijkiae and P. nordicum) [29].

Although several mycotoxin biosynthetic pathways have been elucidated, relatively little is known about the molecular mechanisms of OTA biosynthesis. The hypothesis is that the biosynthesis of OTA follows the subsequent pathway: backbone polyketide (possibly $7-\mathrm{MM}) \rightarrow \mathrm{OT} \beta \rightarrow \mathrm{OTB} \rightarrow$ OTA $[12,30]$. Recent advances on the understanding of the OTA biosynthetic pathway were performed by analyzing OTA and its intermediates in both WT and deletion mutants of AcOTApks, AcOTAnrps, and AcOTAhal biosynthetic genes [10-12]. In our study, the deletion of the AcOTAbZIP gene blocks the OTA biosynthesis. According to the HPLC-HRMS analysis, $\triangle A c O T A b Z I P$ strains were unable to synthesize OTB, the precursor of OTA. Additionally, both WT and $\triangle A c O T A b Z I P$ strains did not produce OT $\beta$ probably due to its rapid conversion into OTB in the case of WT and likely due to the deletion of the gene in the $\triangle A c O T A b Z I P$ strains. Finally, 7-MM, proposed as a possible backbone polyketide of the OTA biosynthetic pathway [31], was produced by both the WT and the $\triangle A c O T A b Z I P$ strains in culture filtrates and only by WT in PDA-plugs. Probably, contrary to what happens with the other OTA intermediates (OT $\beta$ and OTB), 7-MM represents the backbone structure for the biosynthesis of different polyketides, including OTA.

The gene expression analysis showed that all analyzed genes (AcOTApks, AcOTAnrps, AcOTAp450, and AcOTAhal) were down-regulated in $\triangle A c O T A b Z I P$ compared to WT strains. Similar results were obtained by the deletion of the AcOTAbZIP orthologue gene OtaR1 in $A$. westerdijkiae fc- 1 in which this gene regulates the expression of the OTA biosynthetic genes. Castellá et al., [16] have also indicated that the down-regulation of the AcOTAbZIP may explain the lack of OTA production in the three non-ochratoxigenic strains analyzed, indicating that this transcription factor is the major regulator of the OTA biosynthesis in A. carbonarius (Figure 5).

It is well known that in filamentous fungi, different genes can be involved in both fungal development and secondary metabolism [32]. For example, in A. carbonarius the deletion of the alb1 gene, the pks involved in the 1,8-dihydroxynaphtalene melanin biosynthesis, affects conidia pigmentation, conidia, and sclerotia production, and the production of OTA and its partitioning into the fungal structures [33]. It has been reported that the deletion of $A c p a c C$ gene, a $\mathrm{pH}$-responsive transcription factor, affects vegetative growth, conidia production, and germination, and OTA production [34]. In the present study, the deletion of the AcOTAbZIP gene did not affect the vegetative growth and conidia production of A. carbonarius growing on different media (MEA, MM, and PDA) compared to WT. The involvement of mycotoxins in the infection process is still under study in the producer fungi. For example, gliotoxin and trichothecenes are recognized as important virulence factors of A. fumigatus and Fusarium graminearum, respectively [35,36]. For patulin, no difference was observed in terms of pathogenicity between patulin producing (PEXP and PEX1) and non-producing (PEX2) P. expansum wild strains. Additionally, in the same fungus, the deletion of pat $K$, pat $L$, and pat $N$, genes directly involved in patulin biosynthesis, resulted in the lack of ability to produce the mycotoxin but not in differences in growth rate, sporulation, and pathogenicity on apple fruits with respect to WT [37]. In our study, both WT and $\triangle A c O T A b Z I P$ strains were inoculated on berries of two table grape cultivars (Italia and Red Globe) to understand the role of OTA as a virulence factor. No differences were observed between WT and $\triangle A c O T A b Z I P$ strains, suggesting that under the tested conditions, OTA is not involved in the plant tissue colonization of $A$. carbonarius on grape berries.

In conclusion, the present study showed the functional role of the AcOTAbZIP gene on the OTA biosynthesis. This gene is conserved in the species carrying a putative-OTA gene cluster and is directly involved in the OTA pathway by regulating the expression of the four biosynthetic genes AcOTApks, AcOTAp450, AcOTAnrps, AcOTAhal. No differences in terms of fitness were observed between WT and $\triangle A c O T A b Z I P$ strains suggesting that OTA is not involved in the virulence of $A$. carbonarius on grapes. 


\section{AcOTAbZIP}
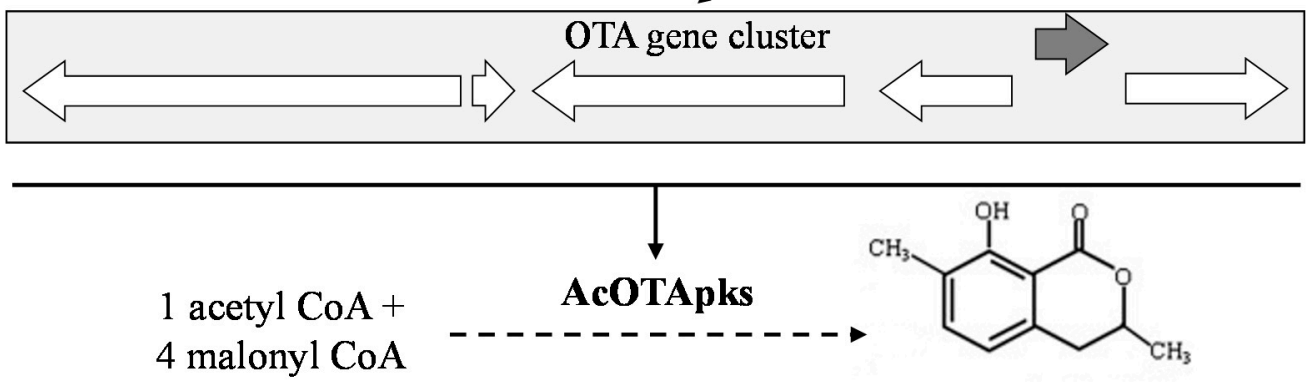

7-methyl mellein (7-MM)

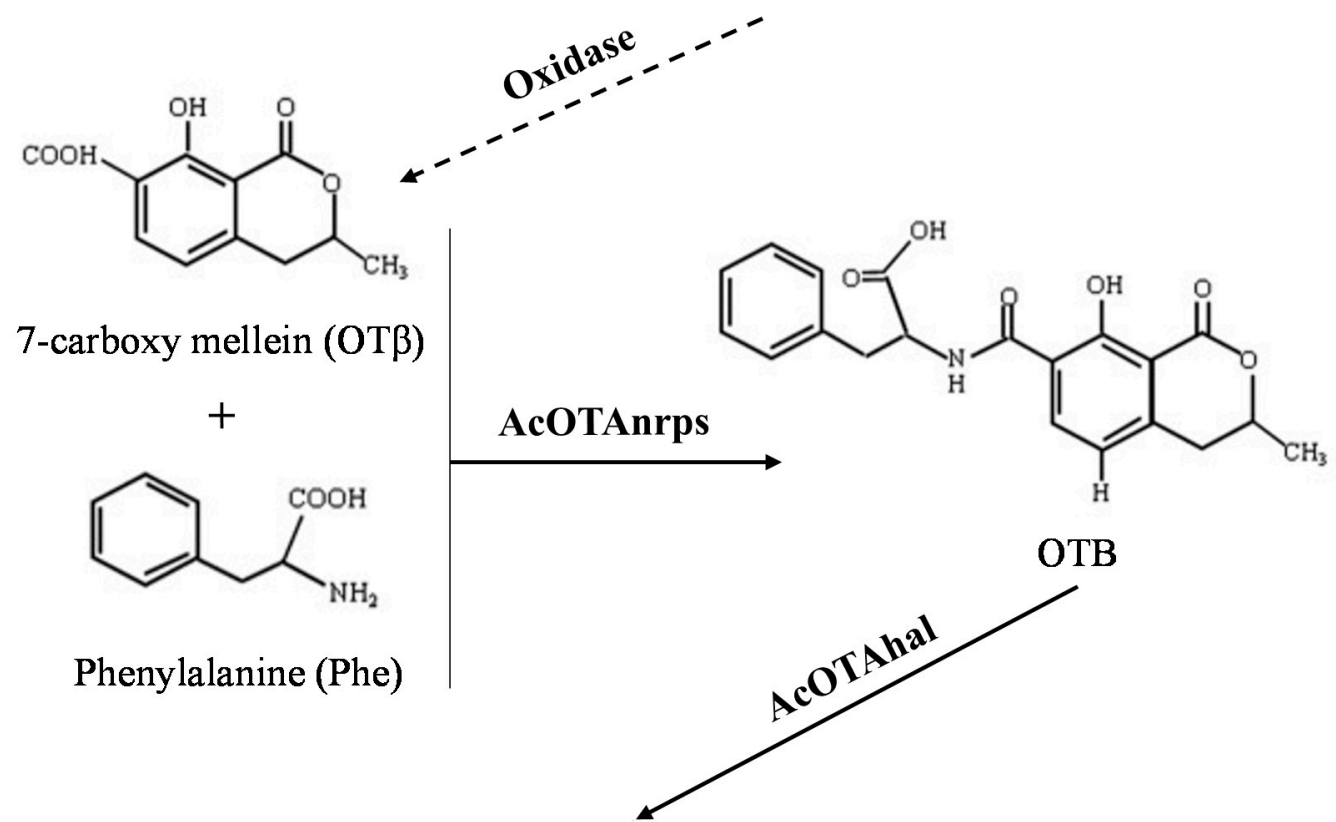<smiles>CC1Cc2c(Cl)cc(C(=O)NC(Cc3ccccc3)C(=O)O)c(O)c2C(=O)O1</smiles>

OTA

Figure 5. Schematic description of the OTA biosynthetic pathway according to [12] and herein obtained results, resuming the functional role of AcOTAbZIP, AcOTApks, AcOTAnrps, and AcOTAhal. Dashed arrows represent the hypothesized enzymatic steps.

\section{Material and Methods}

\subsection{Strains and Media}

The OTA-producing AC49 strain of A. carbonarius was used as WT (Gerin et al., 2016; 2018 ), to generate $\triangle A c O T A b Z I P$ deletion mutants. All strains were routinely grown on potato dextrose agar (PDA; infusion from $200 \mathrm{~g}$ peeled and sliced potatoes kept at $60^{\circ} \mathrm{C}$ for $1 \mathrm{~h}, 20 \mathrm{~g}$ dextrose, adjusted at $\mathrm{pH}$ 6.5, $20 \mathrm{~g}$ agar Oxoid no. 3, per liter). Minimal medium [MM; $10 \mathrm{~mL}$ solution $\mathrm{A}\left(10 \mathrm{~g} \mathrm{KH}_{2} \mathrm{PO}_{4}\right.$, per $100 \mathrm{~mL}$ of water), $10 \mathrm{~mL}$ solution $\mathrm{B}\left(20 \mathrm{~g} \mathrm{NaNO}_{3}, 5 \mathrm{~g} \mathrm{KCl}, 5 \mathrm{~g} \mathrm{MgSO}_{4} \cdot 7 \mathrm{H}_{2} \mathrm{O}, 0.1 \mathrm{~g} \mathrm{FeSO}_{4}\right.$, per $100 \mathrm{~mL}$ of water), $1 \mathrm{~mL}$ of micro-nutritive solution [38], 20 g glucose, $20 \mathrm{~g}$ agar Oxoid no. 3, per liter], malt extract 
agar (MEA: $20 \mathrm{~g}$ malt extract and $20 \mathrm{~g}$ agar Oxoid no. 3, per liter) and PDA were used in phenotypic characterization and to evaluate OTA production.

\subsection{Identification and Characterization of AcOTAbZIP Gene}

The features of the AcOTAbZIP gene were analyzed in the Doe Joint Genome Institute portal (https:/ / mycocosm.jgi.doe.gov/cgi-bin/dispGeneModel?db=Aspca3\&id=7821). The whole protein sequence was submitted to NPS@ using the "Secondary structure consensus prediction" tool [39] to predict $\alpha$-helices, random coil, and other protein features.

The AcOTAbZIP transcription factor (ID: 7821) of A. carbonarius was used for the BLASTp analysis to identify the orthologue genes in other Aspergillus and Penicillium species (https://genome.jgi.doe.gov). For each fungal species, the identified gene was considered an OTAbZIP transcription factor if it was clustered with the orthologue genes of A. carbonarius AcOTApks, AcOTAnrps, AcOTAP450, and AcOTAhal. All OTAbZIP proteins of different fungal species and also all bZIP proteins present in the $A$. carbonarius genome were downloaded (https: / / genome.jgi.doe.gov). The nucleotide sequence of OTAbZIP was firstly identified into the $A$. westerdijkiae fc-1 assembled genome (www.ncbi.nlm.nih.gov/ assembly /GCA_004849945.1), by BLASTn using the A. westerdijkiae CBS 112803 OTAbZIP as the query sequence, because the proteome of the target fungus is still lacking. Then protein sequence was obtained by using the ExPaSy translation tool (http:/ / expasy.org/tools/dna. html). For each bZIP sequence, the BRLZ domain was obtained by using SMART [40] and used for performing phylogenetic analysis with the Maximum Likelihood method (ML) and JTT matrix-based model in MEGAX software [41].

To better identify the conserved regions ( $N-x 7-R / K$, into $B R$ and leucine repeats into LZ) into BRLZ, domains motifs were predicted by using Multiple EM for Motif Elicitation (MEME) tool in the Motif-based sequence analysis tools (MEME Suite 5.1.0; [42]). Additionally, the MEME tool was used to examine the presence of the putative-Transcription Factor Binding Motifs (TFBMs) into the entire nucleotide sequences of upstream, downstream, and intergenic regions of each putative OTA-gene cluster in the listed OTA producing fungi (Table S1). For A. carbonarius, untranslated (UTR) regions of each gene of the cluster were also included, because it was recently reported that the control of gene expression can be UTR-dependent [43]. The most representative motif was then used in the Motif Comparison Tool (Tomtom, MEME Suite 5.1.0) to analyze its similarity with TFBMs present in the motif database of JASPAR CORE (2018) fungi with a cut-off $p$-value of 0.01 .

\subsection{Deletion of AcOTAbZIP Gene in A. carbonarius}

All primer pairs were designed with the Primer3 software [44]. The amplification of the promoter and the terminator regions $(\sim 1.5 \mathrm{~kb})$ from A. carbonarius AC49 genomic DNA was performed using Top-Taq DNA polymerase (Bioron $\mathrm{GmbH}$, Ludwigshafen, Germany), according to the manufacturer's instructions, and using the primer pairs AcOTAbZIP_O1/AcOTAbZIP_O2 and AcOTAbZIP_A3/AcOTAbZIP_A4 for the promoter and terminator regions of the AcOTAbZIP gene, respectively (Table 2). PCR conditions were $94{ }^{\circ} \mathrm{C}$ for $3 \mathrm{~min}, 35$ cycles of $94{ }^{\circ} \mathrm{C}$ for $15 \mathrm{~s}, 58^{\circ} \mathrm{C}$ for $20 \mathrm{~s}$, and $72{ }^{\circ} \mathrm{C}$ for $2 \mathrm{~min}$, and a final stage at $72{ }^{\circ} \mathrm{C}$ for $10 \mathrm{~min}$. The plasmid pRFHU2-AcOTAbZIP was obtained according to Frandsen et al. [45] by incubating the promoter, terminator, and PacI/Nt.BbvCI-digested pRFHU2 (ratio 30:30:120 ng) and $1 \mu \mathrm{L}$ of the Uracil-Specific Excision Reagent (USER) enzyme (New England Biolabs, Ipswich, MA, USA) at $37^{\circ} \mathrm{C}$ for $20 \mathrm{~min}$ followed by $25^{\circ} \mathrm{C}$ for $20 \mathrm{~min}$. 
Table 2. Primers used for the generation, validation, and gene expression analysis of Aspergillus carbonarius $\triangle A c O T A b Z I P$ strains.

\begin{tabular}{|c|c|c|}
\hline Target Region & Primer Name & Primer Sequence $\left(5^{\prime}-3^{\prime}\right)$ \\
\hline \multicolumn{3}{|c|}{ Promoter and terminator amplification in A. carbonarius (AC49) } \\
\hline AcOTAbZIP & AcOTAbZIP_O1 & GGTCTTAAUTGTTGAAGGTGCGGTTCTTG \\
\hline promoter & AcOTAbZIP_O2 & GGCATTAAUCATGAGCATTGACACGAGCC \\
\hline AcOTAbZIP & AcOTAbZIP_A3 & GGACTTAAUTGAGCGCATGTCTAGCAAAC \\
\hline terminator & AcOTAbZIP_A4 & GGGTTTAAUTCGGCCGTGAAGCAGTTATA \\
\hline \multicolumn{3}{|c|}{ Screening in E. coli (DH5 $\alpha)$} \\
\hline & RF-2 & TCTCCTTGCATGCACCATTCCTTG \\
\hline pRFHU2-AcOTAbZIP & RF-5 & GTTTGCAGGGCCATAGAC \\
\hline plasmid & RF-1 & AAATTTTGTGCTCACCGCCTGGAC \\
\hline & RF-6 & ACGCCAGGGTTTTCCCAGTC \\
\hline \multicolumn{3}{|c|}{ Screening in A. carbonarius (AC49 and $\triangle A c O T A b Z I P$ strains) } \\
\hline AcOTAbZIP & AcOTAbZIP_1F & AGGCGTTATAGGACCAGTCG \\
\hline promoter & HPH1F & ACGAGGTCGCCAACATCTTCTTCT \\
\hline AcOTAbZIP & AcOTAbZIP_2R & CACTCGCTCCTCCGTGATAT \\
\hline terminator & HPHPRO4 & GCACCAAGCAGCAGATGATA \\
\hline \multirow{2}{*}{ Hygromycin B } & HMBF1 & CTGTCGAGAAGTTTCTGATCG \\
\hline & HMBR1 & CTGATAGAGTTGGTCAAGACC \\
\hline \multirow{2}{*}{ AcOTAbZIP } & AcOTAbZIP_3F & CATCCATGCCCCAATTCGAG \\
\hline & AcOTAbZIP_4R & TGCTTGAGGTCTAAGAGTTCCT \\
\hline \multicolumn{3}{|c|}{ T-DNA copy numbers integrated into $A$. carbonarius $\triangle A c O T A b Z I P$ strains genome } \\
\hline \multirow[b]{2}{*}{ AcOTAbZIP } & AcOTAbZIP_CN_F & AATTGACAGCGAGGCGAATC \\
\hline & AcOTAbZIP_CN_R & CCTGCAGCAACTCGATCAAA \\
\hline \multirow{2}{*}{ Calmodulin } & Cal_CN_F & CCTTACCATGATGGCTCG \\
\hline & Cal_CN_R & TTCTCACCGATGGAGGTCAT \\
\hline \multicolumn{3}{|c|}{ RT-PCR and RTqPCR (AC49 and $\triangle A c O T A b Z I P$ strains) } \\
\hline \multirow{2}{*}{ AcOTAbZIP } & bZIPFor & TTTCCCTAGGATCTCTCCTA \\
\hline & bZIPRev & TATTGGGGTCGGACAGGAAT \\
\hline \multirow{2}{*}{ AcOTApks } & pks4For & TCTGTATGAGCGCATCGCC \\
\hline & pks4Rev & GCAGAAGGCCACTTTCCAG \\
\hline \multirow{2}{*}{ AcOTAnrps } & nrps6For & GATTCCGATGGAACTGCAAT \\
\hline & nrps6Rev & CTGCCCCAGCATATCAATCT \\
\hline \multirow{2}{*}{ AcOTAP450 } & P450For & GCCATACCTGACCGGGATCA \\
\hline & P450Rev & GGGAAAATGGTCTCGTCGTG \\
\hline \multirow{2}{*}{ AcOTAhal } & halFor & AAAGAAGCCTACACCGACTT \\
\hline & halRev & GAATTCGATGGATCCCGTGC \\
\hline \multirow{2}{*}{ Ubiquitin } & ubFor & CCGAAGGTCAACTTCACCAC \\
\hline & ubRev & GGCATATTTGCGAGTCCATT \\
\hline
\end{tabular}

Bold: part of the primer useful for the treatment with the USER enzyme mix in the generation of $3^{\prime}$ single-stranded overhangs.

Aliquots $(10 \mu \mathrm{L})$ of the mixture were used for the transformation of chemically competent cells of E. coli DH5 $\alpha$ [45]. After $18 \mathrm{~h}$ of incubation at $37^{\circ} \mathrm{C}$ on Luria-Bertani (LB) agar medium (bacto tryptone $10 \mathrm{~g}$, yeast extract $5 \mathrm{~g}, \mathrm{NaCl} 5 \mathrm{~g}$, agar $14 \mathrm{~g}$, per liter) supplemented with $25 \mu \mathrm{g} \mathrm{mL}^{-1}$ of kanamycin (Invitrogen, Carlsbad, CA, USA), resistant colonies were first screened by PCR using the primer pairs RF-5/RF-2 and RF-1/RF-6 (Table 2) and the fusion was confirmed by using the primers RF-2/AcOTAbZIP_O1 and RF-1/AcOTAbZIP_A4.

The plasmid pRFHU2-AcOTAbZIP was then introduced in electrocompetent cells of A. tumefaciens AGL-1. A. carbonarius AC49 transformants were obtained and screened according to the Agrobacterium tumefaciens mediated transformation (ATMT)-procedure described by Gerin et al. [33]. In particular, for all transformants the integration of the T-DNA in the target region was verified by PCR by using the subsequent primer pairs: (a) $1 \mathrm{~F} / \mathrm{HPH} 1 \mathrm{~F}$ for the promoter; (b) $2 \mathrm{R} / \mathrm{HPHPRO} 4$ for the terminator; (c) $3 \mathrm{~F} / 4 \mathrm{R}$ for the 
deletion of the gene of interest (GOI), and (d) primers HMBF1/HMBR1 for replacement of $\mathrm{GOI}$ with HygB. The determination of the number of T-DNA integrations in the genome of the transformants was assessed by qPCR (primers 3F/4R) using the calmodulin gene (cal; ID: 205510 primers cal_CN_F/cal_CN_R) as a reference (Table 2), as described by Gerin et al. [33].

\subsection{Phenotypic Characterization and In Vivo Assay}

Three A. carbonarius AcOTAbZIP ( $\triangle$ AcOTAbZIP-1, $\triangle A c O T A b Z I P-2$, and $\triangle A c O T A b Z I P-3$ ) deletion mutants were selected and compared with the WT strain for colony growth and production of conidia on three different media (PDA MM and MEA). Mycelial plugs of $4 \mathrm{~mm}$ in diameter from the edges of actively growing colonies were used to inoculate three replicated Petri dishes that were kept at $25 \pm 1{ }^{\circ} \mathrm{C}$ in the darkness. The orthogonal diameters of developing colonies were measured at 2, 5, and 7 days after inoculation (DAI). Additionally, the production of conidia was determined in three agar plugs $(4 \mathrm{~mm}$ diameter) with mycelium and conidia collected from the inner, middle, and outer positions of 7-day-old growing colonies [24].

For each strain, three replicated groups of five ripe table-grape berries cvs Italia and Red Globe collected from two bunches each were surface-sterilized with $2 \%$ sodium hypochlorite for $1 \mathrm{~min}$, rinsed three times with sterile distilled water, and airdried. Conidia were collected by scraping in sterile water containing $0.01 \%$ tween 20 the surface of 7-day-old colonies grown on PDA, and suspensions were adjusted to $10^{6}$ conidia $\mathrm{mL}^{-1}$. Aliquots $(10 \mu \mathrm{L})$ of the conidial suspensions were singly placed on the berry skin, which was then wounded with a needle (3-mm-deep) under the drop. Berries were kept under $100 \%$ relative humidity. After 7 and $10 \mathrm{DAI}$ at $25 \pm 1{ }^{\circ} \mathrm{C}$ in darkness, the orthogonal diameters of the developing lesion were measured. Ten replicated berries inoculated with sterile water were used as control.

In both, in vitro and in vivo assays, the growth rate of colonies or rotted areas $\left(\mathrm{mm}\right.$ day $\left.^{-1}\right)$ was obtained from the average of the ratios between the diameters $(\mathrm{mm})$ and the number of days of incubation $(2,5$, and 7 days for in vitro colony growth assay and 7 and 10 days for in vivo pathogenicity assay, respectively).

\subsection{Analysis of OTA and Its Intermediates}

The preliminary analysis of OTA production by A. carbonarius WT and $\triangle A c O T A b Z I P$ strains was performed on methanol extracts from agar plugs collected from 7 DAI colonies grown on PDA. Briefly, three 6-mm plugs of PDA (collected from the inner, middle, and outer part of the colony) were vortexed for $2 \mathrm{~min}$ in $500 \mu \mathrm{L}$ of methanol, incubated at room temperature for $1 \mathrm{~h}$, filtered on a $0.22 \mu \mathrm{m}$ filter, and stored at $-20^{\circ} \mathrm{C}$ until the HPLC analysis which was performed as described by Gerin et al. [33]. No differences in terms of OTA production among the three selected $\triangle A c O T A b Z I P$ strains were observed and then only the $\triangle A c O T A b Z I P-1$ and the WT strain were used for the subsequent analysis of OTA and its possible intermediates. The analyses were performed on agar plugs from 7-DAI colonies grown on PDA as well as from culture filtrates from MM static cultures at 6 DAI [14]. Three technical replicates were performed. OTA and its intermediates (phenylalanine (Phe), 7-methylmellein (7-MM), ochratoxin $\beta$ (OT $\beta)$, ochratoxin $B(\mathrm{OTB})[10,12])$ were quantified with a TripleTOF 5600 (AB SCIEX, Framingham, MA, USA) LC/MS/MS System with electrospray ionization operated in positive mode. The column was a Kinetix XB-C18 column $(100 \mathrm{~mm}$ by $2.1 \mathrm{~mm}, 1.7 \mu \mathrm{m}$ particles, $100 \AA$ A Phenomenex Inc., Torrance, CA, USA). The mobile phase was a multistep gradient of water (eluent $A$ ) and methanol (eluent B), both containing $0.5 \%$ acetic acid and $1 \mathrm{mM}$ ammonium acetate. Gradient elution was performed by changing the mobile phase composition as follows. After $5 \mathrm{~min}$ at $20 \%$ eluent $\mathrm{B}$, the proportion was set at $40 \%$ and then linearly increased to $63 \%$ in $30 \mathrm{~min}$ and kept constant for $5 \mathrm{~min}$. The column was re-equilibrated with $20 \%$ eluent B for $10 \mathrm{~min}$ before the successive injection. The data acquisition used was in positive mode, over a mass range of $80-1000 \mathrm{~m} / z$. Automated calibration was performed using an external calibrant 
delivery system (CDS) which infuses calibration solution before sample introduction. The MS analysis was performed with the following parameters: $5500 \mathrm{~V}$ ion spray voltage (ISVF); $30 \mathrm{~V}$ collision energy (CE); $350{ }^{\circ} \mathrm{C}$ temperature with 30 psi curtain gas (CU); 50 psi for both ion source gas 1 (GC1) and ion source gas 2 (GS2). Data were evaluated using the PeakViewTM software.

\subsection{Gene Expression Studies by RT-qPCR}

Total RNA was extracted by 4-day-old cultures of $\triangle A c O T A b Z I P-1 / 3$ and WT strains grown in liquid $\mathrm{MM}$ in darkness at $25 \pm 1{ }^{\circ} \mathrm{C}$ (OTA inducing conditions, [14]) using the RNeasy Plant Mini Kit (Qiagen, Milan, Italy) according to the manufacturer's instructions. First-strand cDNA was synthesized from $1 \mu \mathrm{g}$ of RNA using M-MLV reverse transcriptase (Life Technologies, Milan, Italy) and random primers in a volume of $20 \mu \mathrm{L}$, according to the manufacturer's instructions. The expression of genes included in the putative OTA gene cluster (AcOTApks, AcOTAnrps, AcOTAP450, and AcOTAhal) was assessed by using a real-Time PCR Detection System CFX96TM (Bio-Rad Laboratories, Hercules CA, USA) in a volume of $25 \mu \mathrm{L}$ containing $12.5 \mu \mathrm{L}$ of iQ SYBR Green SuperMix (Bio-Rad Laboratories), $0.5 \mu \mathrm{M}$ of each primer and $1 \mu \mathrm{L}$ of the reverse transcription reaction. All primer pairs were designed with the Primer3 software, and where possible, the forward ones were designed on the exon-intron junction sites to avoid amplification of possible contaminant genomic DNA (Table S1). The conditions for amplification were as follows: 3 min denaturation at $95^{\circ} \mathrm{C}$ followed by 35 cycles of $95^{\circ} \mathrm{C}$ for $10 \mathrm{~s}$ and $60^{\circ} \mathrm{C}$ for $45 \mathrm{~s}$. The gene encoding ubiquitin ( $u b$; ID:393986) was used as a reference gene. Relative gene expression was calculated using CFX Manager Software (Bio-Rad Laboratories) and the $2^{-\Delta \Delta C T}$ method [46]. All samples were analyzed in triplicate. For all analyzed genes, the ratio of the gene expression value (fold change) between each deletion mutants and the WT strain was calculated.

Supplementary Materials: The following are available online at https://www.mdpi.com/2072 $-6651 / 13 / 2 / 111 / s 1$, Table S1: Location of the putative-OTA-gene cluster in the genome of the Aspergillus species and Penicillium nordicum. ${ }^{*}$ position of OTA-gene cluster in the fungal genome ( genome.jgi.doe.gov) identified based on homology with OTA putative gene cluster of $A$. carbonarius. Table S2: Features of BRLZ domains used in the Maximum Likelihood phylogenetic analysis. Table S3: Detail of the Transcription factor binding motif (TFBM) identified by MEME in the OTA-gene cluster upstream, downstream, and intergenic sequences. Table S4: TOMTOM analysis representing the homology of TFBM identified by MEME with those of Saccharomyces cerevisiae. * Name of transcription factor binding motif (TFBM) according to the JASPAR database.

Author Contributions: D.G., S.P., F.F., A.-R.B., R.M.D.M.A., and L.G.-C. conceived and designed the experiments; D.G., F.G., and A.-R.B. performed the experiments; D.G., F.G., S.P., F.F., A.-R.B., and L.G.-C. analyzed the data; D.G., F.G., S.P., and A.-R.B. wrote the paper, D.G., S.P., F.F., R.M.D.M.A., A.R.B., and L.G.-C. supervised the writing, D.G., S.P., F.F., R.M.D.M.A., A.-R.B., and L.G.-C. coordinated the collaboration of the authors. All authors have read and agreed to the published version of the manuscript.

Funding: The work was partially co-funded by the University of Bari Aldo Moro for the project "Epidemiology, genetics of plant pathogens and development of molecular diagnostic methods", and from the Apulia Region, PO FESR 2007-2013-Axis I, Line of intervention 1.2., Action 1.2.1 for the project "Laboratory network for the selection, characterization, and conservation of germplasm and for preventing the spread of economically-relevant and quarantine pests (SELGE) No. 14" and by FEDER/Ministerio de Ciencia, Innovación y Universidades-Agencia Estatal de Investigación (AGL2017-28120-R and RTI2018-093392-A-I00).

Institutional Review Board Statement: Not applicable.

Informed Consent Statement: Not applicable.

Data Availability Statement: Data is contained within the article or supplementary material.

Acknowledgments: Ramón y Cajal postdoctoral contract (RyC2017-22009, MINECO, and FSE) to A.-R.B. is also acknowledged. 
Conflicts of Interest: The authors declare no conflict of interest.

\section{References}

1. International Agency for Research on Cancer (IARC). IARC Monographs on the Evaluation of the Carcinogenic Risks to Humans; IARC: Lyon, France, 1993; Volume 56, pp. 489-521.

2. Abarca, M.L.; Accensi, F.; Bragulat, M.R.; Castella, G.; Cabanes, F.J. Aspergillus carbonarius is the main source of ochratoxin A contamination in dried vine fruits from the Spanish market. J. Food Protect. 2003, 66, 504-506. [CrossRef] [PubMed]

3. Amezqueta, S.; Schorr-Galindo, S.; Murillo-Arbizu, M.; Gonzalez-Peñas, E.; De Cerain, A.L.; Guiraud, J.P. OTA-producing fungi in foodstuffs: A review. Food Control 2012, 26, 259-268. [CrossRef]

4. Cabañes, F.J.; Bragulat, M.R.; Castellá, G. Ochratoxin A producing species in the genus Penicillium. Toxins 2010, 2, 1111-1120. [CrossRef] [PubMed]

5. Gil-Serna, J.; Patiño, B.; Cortes, L.; Gonzalez-Jaen, M.T.; Vazquez, C. Aspergillus steynii and Aspergillus westerdijkiae as potential risk of OTA contamination in food products in warm climates. Food Microbiol. 2015, 46, 168-175. [CrossRef] [PubMed]

6. Perrone, G.; Gallo, A. Aspergillus Species and Their Associated Mycotoxins; Mycotoxigenic Fungi Humana Press: New York, NY, USA, 2017; pp. 33-49.

7. Perrone, G.; Susca, A.; Cozzi, G.; Ehrlich, K.; Varga, J.; Frisvad, J.C.; Meijer, M.; Noonim, P.; Mahakarnchanakul, W.; Samson, R.A. Biodiversity of Aspergillus species in some important agricultural products. Stud. Mycol. 2007, 59, 53-66. [CrossRef] [PubMed]

8. Cabañes, F.J.; Accensi, F.; Bragulat, M.R.; Abarca, M.L.; Castellá, G.; Minguez, S.; Pons, A. What is the source of ochratoxin A in wine? Int. J. Food Microbiol. 2002, 79, 213-215. [CrossRef]

9. Pollastro, S.; Dongiovanni, C.; Abbatecola, A.; Tauro, G.; Natale, P.; Pascale, M.; Visconti, A.; Faretra, F. Wine contamination by ochratoxin A in South Italy: Causes and preventive actions. J. Plant Pathol. 2003, 85, 281.

10. Gallo, A.; Bruno, K.S.; Solfrizzo, M.; Perrone, G.; Mulè, G.; Visconti, A.; Baker, S.E. New insight into the ochratoxin A biosynthetic pathway through deletion of a nonribosomal peptide synthetase gene in Aspergillus carbonarius. Appl. Environ. Microb. 2012, 78, 8208-8218. [CrossRef] [PubMed]

11. Gallo, A.; Knox, B.P.; Bruno, K.S.; Solfrizzo, M.; Baker, S.E.; Perrone, G. Identification and characterization of the polyketide synthase involved in ochratoxin A biosynthesis in Aspergillus carbonarius. Int. J. Food Microbiol. 2014, 179, 10-17. [CrossRef] [PubMed]

12. Ferrara, M.; Perrone, G.; Gambacorta, L.; Epifani, F.; Solfrizzo, M.; Gallo, A. Identification of a halogenase involved in the biosynthesis of ochratoxin A in Aspergillus carbonarius. Appl. Environ. Microb. 2016, 82, 5631-5641. [CrossRef]

13. Ferrara, M.; Gallo, A.; Perrone, G.; Magistà, D.; Baker, S.E. Comparative genomic analysis of ochratoxin A biosynthetic cluster in producing fungi: New evidence of a cyclase gene involvement. Front. Microbiol. 2020, 11, 3289.

14. Gerin, D.; De Miccolis Angelini, R.M.; Pollastro, S.; Faretra, F. RNA-Seq reveals OTA-related gene transcriptional changes in Aspergillus carbonarius. PLoS ONE 2016, 11, e0147089. [CrossRef] [PubMed]

15. Castellá, G.; Bragulat, M.R.; Puig, L.; Sanseverino, W.; Cabañes, F.J. Genomic diversity in ochratoxigenic and non ochratoxigenic strains of Aspergillus carbonarius. Sci. Rep. 2018, 8, 1-11. [CrossRef] [PubMed]

16. Castellá, G.; Bragulat, M.R.; Cigliano, R.A.; Cabañes, F.J. Transcriptome analysis of non-ochratoxigenic Aspergillus carbonarius strains and interactions between some black aspergilli species. Int. J. Food Microbiol. 2020, 317, 108498. [CrossRef] [PubMed]

17. Gil-Serna, J.; Vázquez, C.; Patiño, B. The Genomic Regions That Contain Ochratoxin A Biosynthetic Genes Widely Differ in Aspergillus Section Circumdati Species. Toxins 2020, 12, 754. [CrossRef] [PubMed]

18. Wang, Y.; Wang, L.; Wu, F.; Liu, F.; Wang, Q.; Zhang, X.; Selvaraj, J.N.; Zhao, Y.; Xing, F.; Yin, W.-B.; et al. A consensus ochratoxin A biosynthetic pathway: Insights from the genome sequence of Aspergillus ochraceus and a comparative genomic analysis. Appl. Environ. Microb. 2018, 84, e01009-e01018. [CrossRef] [PubMed]

19. Marzluf, G.A. Genetic regulation of nitrogen metabolism in the fungi. Microbiol. Mol. Biol. Rev. 1997, 61, 17-32. [CrossRef] [PubMed]

20. Mihlan, M.; Homann, V.; Liu, T.W.D.; Tudzynski, B. AREA directly mediates nitrogen regulation of gibberellin biosynthesis in Gibberella fujikuroi, but its activity is not affected by NMR. Mol. Microbiol. 2003, 47, 975-991. [CrossRef]

21. Tilburn, J.; Sarkar, S.; Widdick, D.A.; Espeso, E.A.; Orejas, M.; Mungroo, J.; Peñalva, M.A.; Arst, H.N., Jr. The Aspergillus PacC zinc finger transcription factor mediates regulation of both acid-and alkaline-expressed genes by ambient pH. EMBO J. 1995, 14, 779-790. [CrossRef]

22. Dowzer, C.E.; Kelly, J.M. Analysis of the creA gene, a regulator of carbon catabolite repression in Aspergillus nidulans. Mol. Cell. Biol. 1991, 11, 5701-5709. [CrossRef]

23. Espeso, E.A.; Peñalva, M.A. Carbon catabolite repression can account for the temporal pattern of expression of a penicillin biosynthetic gene in Aspergillus nidulans. Mol. Microbiol. 1992, 6, 1457-1465. [CrossRef] [PubMed]

24. Crespo-Sempere, A.; Marin, S.; Sanchis, V.; Ramos, A.J. VeA and LaeA transcriptional factors regulate ochratoxin A biosynthesis in Aspergillus carbonarius. Int. J. Food Microbiol. 2013, 166, 479-486. [CrossRef] [PubMed]

25. Ehrlich, K.C.; Montalbano, B.G.; Cary, J.W. Binding of the C6-zinc cluster protein, AFLR, to the promoters of aflatoxin pathway biosynthesis genes in Aspergillus parasiticus. Gene 1999, 230, 249-257. [CrossRef] 
26. Jiang, C.; Zhang, C.; Wu, C.; Sun, P.; Hou, R.; Liu, H.; Wang, C.; Xu, J.R. TRI6 and TRI10 play different roles in the regulation of deoxynivalenol (DON) production by cAMP signalling in Fusarium graminearum. Environ. Microbiol. 2016, 18, 3689-3701. [CrossRef] [PubMed]

27. Landschulz, W.H.; Johnson, P.F.; McKnight, S.L. The leucine zipper: A hypothetical structure common to a new class of DNA binding proteins. Science 1988, 240, 1759-1764. [CrossRef]

28. Vinson, C.; Acharya, A.; Taparowsky, E.J. Deciphering B-ZIP transcription factor interactions in vitro and in vivo. BBA-Gene Struct. Expr. 2006, 1759, 4-12. [CrossRef]

29. Gil-Serna, J.; García-Díaz, M.; González-Jaén, M.T.; Vázquez, C.; Patiño, B. Description of an orthologous cluster of ochratoxin A biosynthetic genes in Aspergillus and Penicillium species. A comparative analysis. Int. J. Food Microbiol. 2018, 268, 35-43. [CrossRef]

30. Huffman, J.; Gerber, R.; Du, L. Recent advancements in the biosynthetic mechanisms for polyketide derived mycotoxins. Biopolymers 2010, 93, 764-776. [CrossRef]

31. Huff, W.E.; Hamilton, P.B. Mycotoxins-their biosynthesis in fungi: Ochratoxins-metabolites of combined pathways. J. Food Protect. 1979, 42, 815-820. [CrossRef]

32. Calvo, A.M.; Wilson, R.A.; Bok, J.W.; Keller, N.P. Relationship between secondary metabolism and fungal development. Microbiol. Mol. Biol. Rev. 2002, 66, 447-459. [CrossRef]

33. Gerin, D.; González-Candelas, L.; Ballester, A.R.; Pollastro, S.; De Miccolis Angelini, R.M.; Faretra, F. Functional Characterization of the alb1 Orthologue Gene in the Ochratoxigenic Fungus Aspergillus carbonarius (AC49 strain). Toxins 2018, 10, 120. [CrossRef] [PubMed]

34. Barda, O.; Maor, U.; Sadhasivam, S.; Bi, Y.; Zakin, V.; Prusky, D.; Sionov, E. The pH-Responsive Transcription Factor PacC Governs Pathogenicity and Ochratoxin A Biosynthesis in Aspergillus carbonarius. Front. Microbiol. 2020, 11, 210. [CrossRef] [PubMed]

35. Hof, H.; Kupfahl, C. Gliotoxin in Aspergillus fumigatus: An example that mycotoxins are potential virulence factors. Mycotoxin Res. 2009, 25, 123. [CrossRef] [PubMed]

36. Harris, L.J.; Desjardins, A.E.; Plattner, R.D.; Nicholson, P.; Butler, G.; Young, J.C.; Weston, G.; Proctor, R.H.; Hohn, T.M. Possible role of trichothecene mycotoxins in virulence of Fusarium graminearum on maize. Plant Dis. 1999, 83, 954-960. [CrossRef] [PubMed]

37. Ballester, A.R.; Marcet-Houben, M.; Levin, E.; Sela, N.; Selma-Lázaro, C.; Carmona, L.; Wisniewski, M.; Droby, S.; GonzálezCandelas, L.; Gabaldón, T. Genome, transcriptome, and functional analyses of Penicillium expansum provide new insights into secondary metabolism and pathogenicity. Mol. Plant Microbe Interact. 2015, 28, 232-248. [CrossRef]

38. Sanderson, K.E.; Srb, A.M. Heterokaryosis and parasexuality in the fungus Ascochyta imperfecta. Am. J. Bot. 1965, 52, 72-81. [CrossRef]

39. Combet, C.; Blanchet, C.; Geourjon, C.; Deleage, G. NPS@: Network protein sequence analysis. Trends Biochem. Sci. 2000, 25, 147-150. [CrossRef]

40. Ponting, C.P.; Schultz, J.; Milpetz, F.; Bork, P. SMART: Identification and annotation of domains from signalling and extracellular protein sequences. Nucleic Acids Res. 1999, 27, 229-232. [CrossRef]

41. Kumar, S.; Stecher, G.; Li, M.; Knyaz, C.; Tamura, K. MEGA X: Molecular Evolutionary Genetics Analysis across computing platforms. Mol. Biol. Evol. 2018, 35, 1547-1549. [CrossRef]

42. Bailey, T.L.; Johnson, J.; Grant, C.E.; Noble, W.S. The MEME suite. Nucleic Acids Res. 2015, 43, W39-W49. [CrossRef]

43. Srivastava, A.K.; Lu, Y.; Zinta, G.; Lang, Z.; Zhu, J.K. UTR-dependent control of gene expression in plants. Trends Plant Sci. 2018, 23, 248-259. [CrossRef] [PubMed]

44. Untergasser, A.; Cutcutache, I.; Koressaar, T.; Ye, J.; Faircloth, B.C.; Remm, M.; Rozen, S.G. Primer3—New capabilities and interfaces. Nucleic Acids Res. 2012, 40, e115. [CrossRef] [PubMed]

45. Frandsen, R.J.; Andersson, J.A.; Kristensen, M.B.; Giese, H. Efficient four fragment cloning for the construction of vectors for targeted gene replacement in filamentous fungi. BMC Mol. Biol. 2008, 9, 70. [CrossRef] [PubMed]

46. Livak, K.J.; Schmittgen, T.D. Analysis of relative gene expression data using real-time quantitative PCR and the $2^{-\Delta \Delta C T}$ method. Methods 2001, 25, 402-408. [CrossRef] [PubMed] 